\title{
Conversion of Cyclamate to Cyclohexylamine in Guinea Pigi)
}

\author{
Masato Asahina, Tsutomu Yamaha, ${ }^{2 a)}$ Ginette Sarrazin, ${ }^{2 b}$ ) \\ and KUNIKo WATANABE ${ }^{2 c)}$ \\ National Institute of Hygienic Sciences $\left.{ }^{2 a}\right)$
}

(Received June 15, 1971)

\begin{abstract}
Continuous oral administration of sodium cyclamate(CHS-Na) to guinea pig caused the gradual increase of urinary excretion of cyclohexylamine(CHA) after a certain period. The amount of CHA excreted was not only different in individuals, but also dependent on each experiment. It was diminished when CHS-Na was administered orally with antibiotics or intraperitoneally. It was shown from the incubation experiments that apparent accumulation of CHA was observed by cecal contents or feces from the animal excreting CHA in urine by oral administration of $\mathrm{CHS}-\mathrm{Na}$, but not from that diminished the excretion by the above conditions. Any in vitro study using animal tissues failed to detect the accumulation of CHA. Consequently it may be probable to assume the participation of duct microflora in the conversion of $\mathrm{CHS}-\mathrm{Na}$ to $\mathrm{CHA}$ in guinea pig.
\end{abstract}

The urinary excretion of cyclohexylamine (CHA) in laboratory animals ${ }^{3)}$ and humans ${ }^{4}$. after oral administration of sodium cyclamate (CHS-Na) has already been established by many workers, since the original report ${ }^{5)}$ by Kojima and Ichibagase in 1966 . Besides CHA, cyclohexanol (CHnol) and cyclohexanone (CHnone) were excreted in urine of rabbit and rat $^{6)}$ and furthermore cyclohexylglucuronide in human urine. ${ }^{7)}$

In the previous paper ${ }^{8)}$ the present authors ascertained that the variable amounts of CHA were excreted in urine of human volunteers ingested CHS-Na or taking usual meals. Now it is very interesting to know the site and mechanism of the biotransformation of CHS$\mathrm{Na}$ to $\mathrm{CHA}$, but it has not yet been well elucidated whether this conversion occurred in animal tissues or duct microflora, except a few brief reports supporting the respective standpoints. ${ }^{6,9)}$

In this paper the urinary excretion was determined in the guinea pig to which CHS-Na was orally administered with and without antibiotics, or intraperitoneally. At the same time the formation of CHA was compared in the in vitro study of feces, cecal contents and liver homogenate. As the results of these experiments it was suggested that duct microflora took an important part in the conversion of CHS-Na to CHA in guinea pig.

1) A part of this work was presented at thr 91 th Annual Meeting of the Pharmaceutical Society of Japan, Fukuoka, April 1971.

2) Location: a) 18-1, Kamiyoga 1 Chome, Setagaya-ku, Tokyo, 158, Japan; b) Present adress: Faculty of Pharmacy, University of Paris, 4, Avenue de 1'Observatoir, Paris 6e, France; c) Present adress: Chiba Serum Institute, 6-1, Konodai 2 Chome, Ichikawashi, Chiba, 272, Japan.

3) B. L. Oser, S. Carson, and E. E. Vogin, Nature, 220, 178 (1968); W. C. Wallace, E. J. Lechto, and E. A. Brouwer, J. Pharmacol. Exp. Therap., 175, 325 (1970).

4) J.S. Leahy, M. Wakefield, and T. Taylor, Food Cosm. Toxicol., 5, 447 (1967); J.S. Leahy, T. Taylor, and C.J. Rudd, BIBRA Bulletin, 6, 333 (1967); R.C. Sonders and R.G. Wiegand, Toxicol. Appl. Pharmacol., 12, 291 (1968) ; J.H. Wills, E. Jameson, G. Stoewsand, and F. Coulston, Toxicol. Appl. Pharmacol., 12, 292 (1968); T.R.A. Davis, N. Adler, and J.C. Opsahl, Toxicol. Appl. Pharmacol., 15, 106 (1969).

5) S. Kojima and H. Ichibagase, Chem. Pharm. Bull. (Tokyo), 14, 971 (1966).

6) S. Kojima and H. Ichibagase, Chem. Pharm. Bull. (Tokyo), 16, 1851 (1968).

7) S. Kojima and H. Ichibagase, Chem. Pharm. Bull. (Tokyo), 17, 2620 (1969).

8) M. Asahina, T. Yamaha, K. Watanabe, and G. Sarrazin, Chem. Pharm. Bull. (Tokyo), 19, 628 (1971).

9) R.C. Sonders, J.C. Netwal, and R.G. Wiegand, Pharmacologist, 11, 241 (1969); R.T. Williams, Special Lecture at the 91st Annual Meeting of the Pharmaceutical Society of Japan, Fukuoka, April 1971. 


\section{Experimental}

Analytical Methods-CHA, CHnol and CHnone were determined by gas chromatography using Shimadzu-4APF with dual flame ionization detectors, $3 \mathrm{~mm} \times 200 \mathrm{~cm}$ stainless steel column packed with $10 \%$ Carbowax $20 \mathrm{M}$ plus $2.5 \% \mathrm{NaOH}$ on $60-80$ mesh Chromosorb G, column temperature $90^{\circ}$, injector temperature $130^{\circ}$, detector temperature $145^{\circ}$, carrier gas(nitrogen) flow rate $50 \mathrm{ml} / \mathrm{min}$ and injected sample $4 \mu \mathrm{l}$. The retention times of $\mathrm{CHA}$ and $n$-tridecane, the inner standard, were $5.1 \mathrm{~min}$ and 9.1 min respectively. Those of $n$-dodecane, the inner standard, $\mathrm{CHnone}$ and $\mathrm{CHnol}$ were $5.1 \mathrm{~min}, 10.7 \mathrm{~min}$ and 16.2 min respectively.

Materials-Sodium cyclamate(Yoshitomi Pharmaceutical Co.). Other reagents were commercials (reagent grade), if necessary, redistilled before use.

Preparation of Sample- CHA fraction was prepared from urine in the same procedure previously described(Method-2) ${ }^{8)}$ and analysed by gas chromatography. CHnol and CHnone fractions were prepared by concentrating the first $\mathrm{CHCl}_{3}$ layer in Method-2 to approximate $0.2 \mathrm{ml}$ in vacuo at less than $30^{\circ}$ and determined by gas chromatography after adding $0.05 \mathrm{ml}$ of the inner standard solution containing $25 \mu$ g of $n$-dodecane in $\mathrm{CHCl}_{3}$. Usually $24 \mathrm{hr}$ urine was treated after dilution to $60 \mathrm{ml}$ with water. The standard curves of $\mathrm{CHnone}$ and $\mathrm{CHnol}$ recovered from urine were shown in Fig. 1.

In Vitro Study of Feces and Cecal Contents-Feces and cecal contents of guinea pig were homogenized with twice amounts of $1 \% \mathrm{CHS}-\mathrm{Na}$ and $20-30 \mathrm{ml}$ of the homogenate in a test tube $(\phi 18 \times 200 \mathrm{~mm})$ with a cotton plug was incubated under the semi-anaerobic condition for several days at $30^{\circ}$. After dilution of the incubated homogenate to $60 \mathrm{ml}$ with water, $\mathrm{CHA}$ accumulated was determined by the same procedure as in the case of urine.

In Vitro Study of Tissues_L_Liver, kidney and small intestine of guinea pig to which CHS-Na was orally administered for a long time were homogenized with twice amounts of $0.1 \mathrm{~m}$ phosphate buffer ( $\mathrm{pH}$ 7.0). Twenty $\mathrm{ml}$ of the homogenate containing $0.1 \mathrm{~g}$ of $\mathrm{CHS}-\mathrm{Na}$ was incubated in a $100 \mathrm{ml}$ of Erlenmeyer flask for several hours at $37^{\circ}$. After dilution of the incubated homogenate to $60 \mathrm{ml}$ with water, CHA formed was determined by the method described above.

In order to prolong the incubation time, liver was aseptically removed from the body, homogenized with twice amounts of sterilized Krebs-Ringer phosphate buffer $(\mathrm{pH} 7.0)$ containing $1 \% \mathrm{CHS}-\mathrm{Na}$ and incubated for 3 days at $30^{\circ}$. As all the procedure was aseptically done with caution, the putrefaction could be avoided during the incubation period.

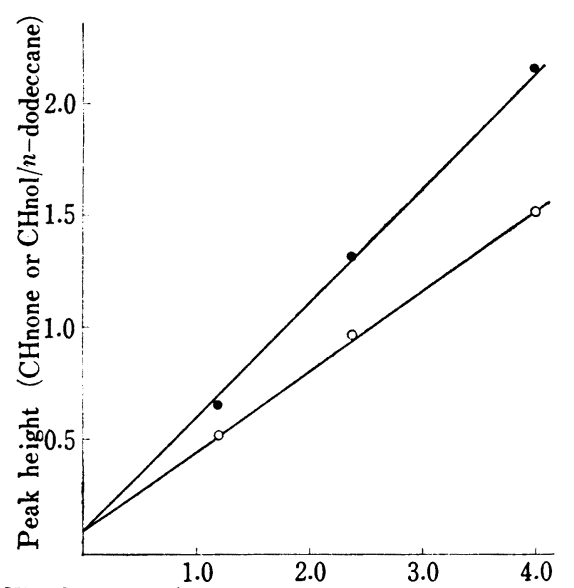

Weight ratio (CHnone or $\mathrm{CHnol} / n$-dodecane)

Fig. 1. Standard Curves of CHnone and CHnol recovered from Urine

-—: CHnone; -O-: $\mathrm{CHnol}$

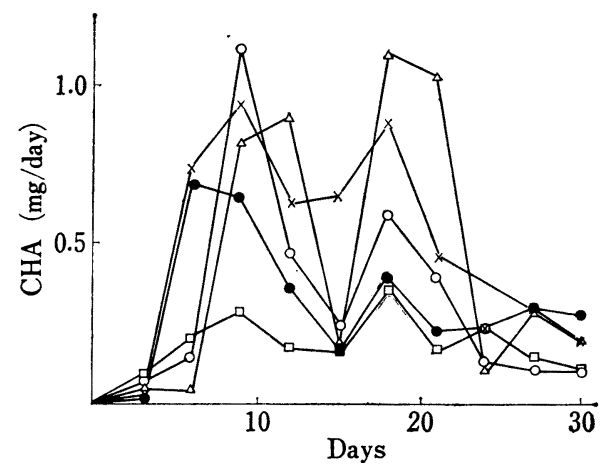

Fig. 2. Excretion of $\mathrm{CHA}$ in Urine of Guinea Pigs taking 1\% CHS-Na as Drinking Water

一-: No. $1 ;-\times-:$ No. $2 ;-1$ - No. 3 ;
$-\triangle-:$ No. $4 ;-\square-:$ No. 5

\section{Result}

\section{Urinary Excretions of CHA, CHnol and CHnone}

Five male guinea pigs $(250-300 \mathrm{~g})$ were given $1 \% \mathrm{CHS}-\mathrm{Na}$ as drinking water and ground commercial feed ad libitum. They actually took about $20-30 \mathrm{ml}$ of $1 \%$ CHS-Na every day. The animals were placed in individual metabolism cages which permitted separate collections of urine from feces. Determining CHA excreted in $24 \mathrm{hr}$ urine every second 
day, as shown in Fig. 2, the amount began to increase rapidly after several days, followed the variable excretion of CHA. Such a type of excretion pattern was thought to be rather a general phenomenon, because the same results could be always obtained in other experiments which would be described later.

In another experiment we found the unexpected result which six of ten male guinea pigs tested died between two weeks and one month after the initiation of oral administration of CHS-Na, with rapid increase of urinary excretion of $\mathrm{CHA}$ and decrease of body weight in several days before the death. Some animal excreted more than $70 \mathrm{mg}$ of CHA per day just before the death (Fig. 3).

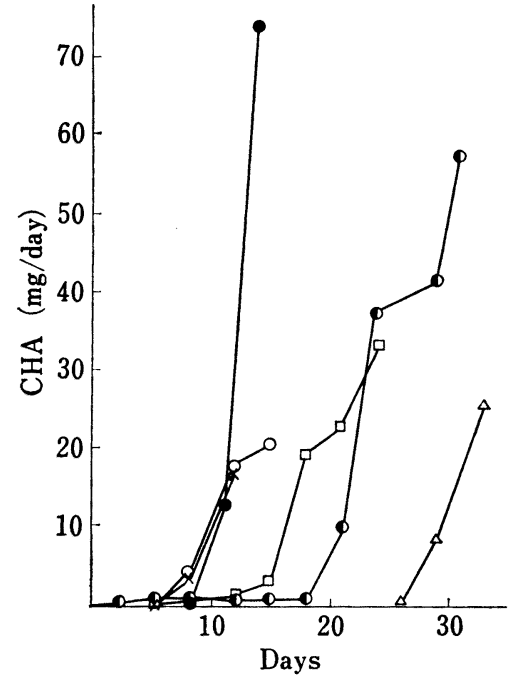

Fig. 3. Excretion of $\mathrm{CHA}$ in Urine of Six died Guinea Pigs taking $1 \%$ CHS-Na as Drinking Water

$$
\begin{aligned}
& \text { - N-: No. } 1(15) ;-\times- \text { : No. } 3(12) \text {; } \\
& -\square-\text { No. } 9(24) ;-\triangle-\text { No. } 8(33) \text {; } \\
& \text { The values in parentheses are the days } \\
& \text { death. }
\end{aligned}
$$

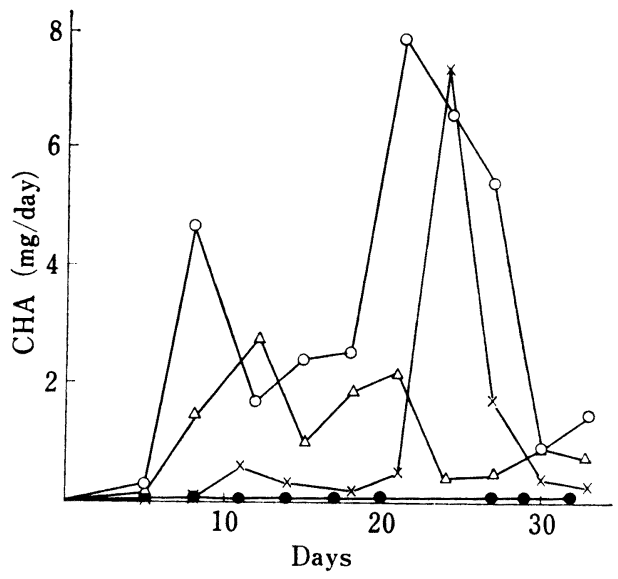

Fig. 4. Excretion of $\mathrm{CHA}$ in Urine of Four survived Guinea Pigs taking $1 \%$ CHS-Na as Drinking Water

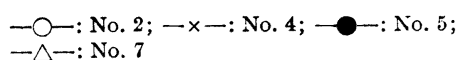

In this experiment, as shown in Fig. 4, even three survived animals except one excreted larger amount of $\mathrm{CHA}$ than the previous experimental group shown in Fig. 2.

The urinary excretion of $\mathrm{CHnol}(0.02-0.5 \mathrm{mg} / \mathrm{day})$ had also a tendency to increase before the death, but there were some exceptions (Fig. 5 and 6). Little or no CHnone was excreted, if any, less than $0.09 \mathrm{mg} /$ day.

As such a extreme phenomenon which guinea pigs died accompaning large amount of urinary excretion of CHA could not be obtained thereafter, it might be probable to assume that some bacteria capable to metabolize CHS-Na to $\mathrm{CHA}$ anomalously grew in the guts and most of the animals were infected by them, taking into consideration of the other experimental results which would be described later.

\section{Comparison of Urinary Excretion of CHA in Intraperitoneal or Oral Administration of CHS-Na} with and without Antibiotics

Seven male guinea pigs $(250-300 \mathrm{~g})$ were placed in individual metabolism cages. $1 \%$ CHS-Na was given as drinking water in group A (No. 1, 2 and 3), 1\% CHS-Na containing $0.01 \%$ streptomycin sulfate and $0.01 \%$ fragiomycin was given as drinking water in group B (No. 4 and 5) and $2 \mathrm{ml}$ of $10 \%$ CHS-Na was intraperitoneally injected every day in group C 


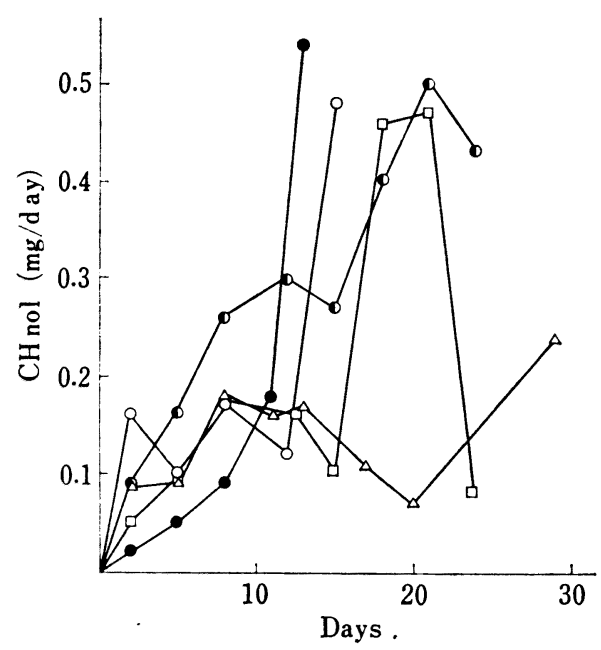

Fig. 5. Excretion of $\mathrm{CHnol}$ in Urine of Six died Guinea Pigs taking 1\% CHS$\mathrm{Na}$

$$
\begin{aligned}
& \text { - No. } 1(15) ;-\times- \text { : No. } 3(12) ; \\
& -1 \text { : No. } 9(24) ;-\triangle-: \text { No. } 8(33) ; \\
& \text { The values in parentheses are the days of death. }
\end{aligned}
$$

(No. 6 and 7). All the animals were permitted to give drinking water and ground commercial feed ad libitum. In these conditions they took about $20-30 \mathrm{ml}$ of the drinking water every day. Twenty four hours urine was collected every second day and CHA excreted was determined.

As Figure 7 shows, the guinea pigs in group A began to excrete CHA in urine after about 10 days followed the repetition of increase and decrease. The maximum values were $1.24 \mathrm{mg} /$ day (39th day) in No. 1, $2.60 \mathrm{mg} /$ day (36th day) in No. 2 and $3.85 \mathrm{mg} /$ day (33rd day) in No. 3 respectively. On the contrary the excretions of $\mathrm{CHA}$ in group $\mathrm{B}$ and $\mathrm{C}$ were less than 0.1 $\mathrm{mg} /$ day.

The weights of guinea pigs in group B did not increase enough because of the long term administration of antibiotics.

\section{In Vitro Study of Cecal Contents}

All the cecal contents were removed from cecum of both guinea pigs given $1 \% \mathrm{CHS}-\mathrm{Na}$ and water (control), and homogenized with $150 \mathrm{ml}$ of $1 \% \mathrm{CHS}-\mathrm{Na}$. Thirty $\mathrm{ml}$ of homogenate in an Erlenmeyer flask with a cotton plug was shaken on a rotary shaker at $30^{\circ}$ (aerobic condition). Another $30 \mathrm{ml}$ of homogenate in a test tube $(\phi 18 \times 200 \mathrm{~mm})$ with a cotton plug was kept at $30^{\circ}$ (semi-anaerobic condition). CHA accumulated in the homogenate was determined at $t=0$ and 4 days. A large amount of $\mathrm{CHA}$ was accumulated in the homo- 
TABLE I. Accumulation of CHA in the Incubation of Cecal Contents with CHS-Na under Aerobic and Semi-anaerobic Conditions

\begin{tabular}{|c|c|c|c|c|}
\hline \multirow{3}{*}{$\begin{array}{l}\text { Incubation time } \\
\text { (days) }\end{array}$} & \multicolumn{4}{|c|}{$\mathrm{CHA}$ accumulated $(\mu \mathrm{g} / 30 \mathrm{ml})$} \\
\hline & \multicolumn{2}{|c|}{ CHS-Na dose } & \multicolumn{2}{|c|}{ Control } \\
\hline & Aerobic & Semi-anaerobic & Aerobic & Semi-anaerobic \\
\hline 0 & 1 & 1 & 4 & 4 \\
\hline 4 & 572 & 3100 & 6 & 6 \\
\hline
\end{tabular}

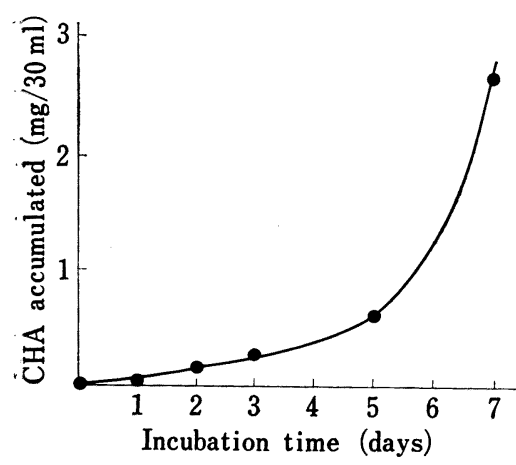

Fig. 8. Accumulation Curve of $\mathrm{CHA}$ in the Incubation of Cecal Contents with CHS-Na under Semi-anaerobic Condition genate of CHS-Na dosed animal, especially under the semi-anaerobic condition (Table I) and the CHA accumulation rapidly increased after several days (Fig. 8).

From these results, all the following in vitro studies of cecal contents and feces were incubated under semianaerobic condition for 5 or 6 days.

Comparing the in vitro study of group A, B, C and control, as shown in Table II, a large amount of CHA was accumulated in group $\mathrm{A}$, while little amount in group B, C and control.

The cecal contents of accidentally died animal in group A (No. 2 in Table II) showed the high level accumulation of $\mathrm{CHA}$ at $t=6$ days and even $t=0$. It was suggested from this fact that the absorption of CHA from duct had ceased after the death of animal

TABLE II. Comparison of CHA accumulated in the in Vitro Study of Cecal Contents of Group A, B, C and Control Guinea Pigs

\begin{tabular}{clccc}
\hline \multicolumn{2}{c}{ Guinea pig used } & \multicolumn{3}{c}{ CHA accumulated $(\mu \mathrm{g} / 30 \mathrm{ml})$} \\
${ } }$ & No. & $t=0$ (day) & $t=3$ (days) & $t=6$ (days) \\
\hline A & $2^{a}$ & 1720 & 9400 & 35400 \\
A & 3 & 11.2 & 411 & 643 \\
B & $5^{a}$ & 4.8 & - & 0 \\
C & 7 & 5.4 & 19.2 & 25.8 \\
Control & - & 0 & 0 \\
\hline
\end{tabular}

a) accidentally died

.causing the accumulation of $\mathrm{CHA}$ in the cecum and that the anomalous growth of duct bacteria capable to utilize CHS-Na furthered a striking increase of CHA accumulation during the incubation time. In the case of group B (No. 5 in Table II) little or no accumulation was shown at $t=0$ or 6 days by the effect of antibiotics.

\section{In Vitro Study of Feces}

The same experiment of in vitro study was performed by using feces of guinea pig under the same conditions as the cecal contents. In the case of group A a significant amount of . $\mathrm{CHA}$ was accumulated during the incubation, but in group $\mathrm{B}$ and $\mathrm{C}$ only $1 / 10-1 / 25$ of that as shown in Table III.

\section{In Vitro Study of Tissue}

In order to ascertain whether CHA is formed in tissue, CHS-Na was incubated with the homogenates of liver, kidney and small intestine of guinea pig which $\mathrm{CHA}$ was excreted 
TABLE III. Comparison of CHA accumulated in the in Vitro Study of Fecal Homogenates of Group A, B and C Guinea Pigs

\begin{tabular}{|c|c|c|c|c|c|}
\hline \multirow{2}{*}{ Exp. } & \multicolumn{2}{|c|}{ Guinea pig used } & \multicolumn{2}{|c|}{$\mathrm{CHA}$ accumulated $(\mu \mathrm{g} / 30 \mathrm{ml})$} & \multirow{2}{*}{$\begin{array}{c}\text { CHA excreted } \\
\text { in urine } \\
(\mu \mathrm{g} / \text { day })\end{array}$} \\
\hline & group & No. & $t=0$ (day) & $t=5^{a)}$ (days) & \\
\hline \multirow[t]{3}{*}{$\mathrm{I}$} & A & 1 & 24.0 & 430 & 269 \\
\hline & $B$ & 5 & 0 & 7.2 & 5.6 \\
\hline & $\mathrm{C}$ & 7 & 0 & 31.4 & 7.6 \\
\hline \multirow[t]{3}{*}{ II } & A & 2 & 132 & 1800 & 829 \\
\hline & $\mathrm{B}$ & 4 & 4.8 & 16.4 & 5.8 \\
\hline & $\mathrm{C}$ & 6 & 4.8 & 96.6 & 94.2 \\
\hline
\end{tabular}

a) $t=6$ (days) in Exp. II

in the urine, but no CHA was accumulated at least for $5 \mathrm{hr}$. No positive results could be obtained in the incubation experiment using microsome or lysozyme fraction of liver. Furthermore the formation of $\mathrm{CHA}$ was not observed for the prolonged incubation time (3 days) in the experiment of liver homogenate under the aseptic condition described in the Method (Table IV).

TABLE IV. Comparison of CHA accumulated in the in Vitro Study of Liver Homogenate and Cecal Contents

\begin{tabular}{|c|c|c|c|c|}
\hline \multicolumn{2}{|c|}{ Guinea pig used } & \multirow{2}{*}{ Homogenate } & \multicolumn{2}{|c|}{ CHA accumulated $\left.(\mu \mathrm{g} / 20 \mathrm{ml})^{a}\right)$} \\
\hline Group & No. & & $t=0$ (day) & $t=3$ (days) \\
\hline \multirow[t]{2}{*}{ A } & 3 & liver & 11.4 & 8.4 \\
\hline & & cecal contents & 11.2 & 411 \\
\hline \multirow[t]{2}{*}{ Control } & - & liver & 7.2 & 8.2 \\
\hline & & cecal contents & 0 & 19.2 \\
\hline
\end{tabular}

a) $(\mu \mathrm{g} / 30 \mathrm{ml})$ in cecal content

\section{Discussion}

When CHS-Na was orally administered to guinea pig every day, the urinary excretion of CHA was gradually increased as observed in other animals and humans. The amount of . $\mathrm{CHA}$ excreted was not only different in individuals, but dependent on each experiment; some time the range was less than one $\mathrm{mg}$, other time several $\mathrm{mg}$ and in one anomalous case reached several tens mg. Such a difference of $\mathrm{CHA}$ excretion level in each experiment might be explained by a possibility that the animals breeded in the same place and time mutually had the similar pattern of duct microflora metabolizing CHS-Na to CHA.

Since Kojima and Ichibagase ${ }^{5)}$ demonstrated the excretion of CHA in urine of experimental animals which CHS-Na was orally administered, it has been a very interesting problem to elucidate the site and mechanism of biotransformation of CHS-Na to CHA. Some workers insisted the participation of tissue enzyme, ${ }^{6)}$ while others that of duct microflora.9)

In this paper we ascertained that the guinea pigs which $\mathrm{CHS}-\mathrm{Na}$ were administered intraperitoneally or orally with antibiotics diminished the excretion of $\mathrm{CHA}$ in urine. At the same time in the incubation experiments of feces and cecal contents with CHS-Na, remarkable amount of CHA was accumulated only in the case of the animal to which CHS-Na was orally administered and CHA was excreted in urine, but little or no CHA was accumulated in the case of simultaneous dose of antibiotics with CHS-Na or intraperitoneal dose of CHS-Na. On the contrary no CHA was formed in the incubation experiment of liver homogenate from any treated guinea pig. 
From the result in this paper, it may be probable to think the participation of duct microflora in the conversion of CHS-Na to CHA; certain microorganisms in the duct were adapted to utilize CHS-Na during the daily contact with CHS-Na for a certain period. As the simultaneous administration of antibiotics with CHS-Na should disturb the normal growth of duct microflora and the intraperitoneal administration of CHS-Na should avoid the direct passage through duct, the diminish of urinary excretion of CHA in both cases would be explained by the assumption that the conditions allowing to grow such microorganisms have not been established.

Furthermore several strains of bacteria capable to assimilate CHS-Na were separated from feces of guinea pig which $\mathrm{CHA}$ was excreted in urine, and the study of the bacterial enzyme system degrading $\mathrm{CHS}-\mathrm{Na}$ is in progress.

Acknowledgement The authors are grateful for Dr. T. Niimura, Department of Medical Chemistry, National Institute of Hygienic Sciences for his helpful advice to bacteriological technique. The authors are also indebted to Miss. Y. Sato, School of Pharmaceutical Sciences, Showa University, for her technical assistance. 